$\begin{array}{lllllllllllllllll}\text { A C T A } & \text { C H E M I C A S C A N D I N A V I C A } & 17 & \text { (1965) } & 567-572\end{array}$

\title{
The Oxidation of 3,5-Diiodotyrosine by Peroxidase and Hydrogen Peroxide
}

\author{
JA N - G UST A F L J U N G GR EN
}

Biochemical Department, Nobel Medical Institute, Stockholm, Sweden

The reaction between 3,5-diiodotyrosine and hydrogen peroxide in the presence of peroxidase has been studied. Some of the oxidation products have been identified by radiochromatography. 3,5-Diiodotyrosine was converted to 4-hydroxy-3,5-diiodophenylpyruvic acid, 4-hydroxy-3,5-diiodobenzaldehyde and 3,5-diiodobenzoquinone. Ammonia, inorganic iodide, 3-iodotyrosine and unknown compounds were also formed.

In a previous paper ${ }^{1}$ 3,5-diiodobenzoquinone was identified as a reaction 1 product from the oxidation of diiodotyrosine by peroxidase and hydrogen peroxide and the possibility of the quinone being an intermediate in the formation of thyroxine from diiodotyrosine was discussed. The reaction mechanism has now been further investigated and attempts have been made to identify the different reaction steps. The presence of the reduced form of this quinone in the thyroid gland of rabbit has recently been reported ${ }^{2}$.

\section{EXPERIMENTAL}

\section{M a terials}

$H R P$, with a purity of $0.7-1.0$, was a generous gift from Professor K.-G. Paul. $D^{131} I T$ was obtained from Abbot Laboratories, USA, and ${ }^{131} I$ from the Radiochemical Centre, England.

$D I H B A$ was prepared according to Paal ${ }^{3}$, m.p. $199-201^{\circ} \mathrm{C}$.

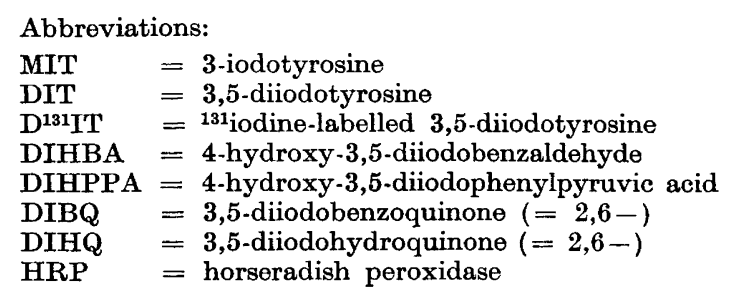

Acta Chem. Scand. 17 (1963) No. 3 
$D I H P P A$ was synthetized according to Siba and Cahnmann " with the exception that the final product was recrystallized the second time from glacial acetic acid instead of aqueous ethanol. USA.

$M I T, D I T$ and Thyroxine were commercial products from Sigma Chemical Company,

All commercial chemicals were of analytical reagent quality and were used without further purification, except that collidine was freshly distilled before use in the paper chromatography experiments.

\section{Methods}

1. The oxidation of $D^{131} I T$ with carrier. The initial mixture for the oxidation of $\mathrm{D}^{131} \mathrm{IT}$ with carrier consisted of $2.5 \times 10^{-3} \mathrm{M} \mathrm{DIT}, 60 \mu \mathrm{C} \mathrm{D} \mathrm{D}^{131} \mathrm{IT}\left(=10^{-5} \mathrm{M}\right.$ ), and $0.9 \mu \mathrm{M} \mathrm{HRP}$ in pH 7.4 0.05 M phosphate buffer. The oxidation was performed at $20^{\circ} \mathrm{C}$ and the volume of the buffered mixture was $12 \mathrm{ml}$. Three $0.12 \mathrm{ml}$ additions of $0.05 \mathrm{M}$ hydrogen peroxide were made during a period of $3 \mathrm{~h}$. During the oxidation process, aliquots of $0.2 \mathrm{ml}$ of the mixture were removed at different time intervals and acidified with $0.05 \mathrm{ml} \mathrm{M}$ sulfuric acid. After placing $0.02 \mathrm{ml}$ of the acidified aliquots on a Whatman No. 1 filter paper, the spots were developed with collidine:water $(100: 35.5 \mathrm{v} / \mathrm{v})$ in an atmosphere of ammonia ${ }^{6}$. A descending system was used. After drying the paper was radioautographed according to standard procedure with the use of Kodak Industrex, type D, X-ray film.

After $3 \mathrm{~h} 5 \mathrm{ml}$ of the reaction mixture was precipitated with $50 \mathrm{mg}$ TCA in order to remove HRP and the precipitate was removed by centrifugation. The supernatant was analyzed by column chromatography according to Spackman et al. 5 The separation was carried out on two columns, one long and one short. The long column $(0.9 \times 150 \mathrm{~cm}$ with ion exchange resin type $150 \mathrm{~A}$ No. $120-212$, obtained from Beckman Instr. Inc., USA) was eluted with $0.2 \mathrm{~N}$ citrate $\mathrm{pH} 3.25$ and $\mathrm{pH} 4.25$. The short column $(0.9 \times 15 \mathrm{~cm}$ with resin type 15A No. $120-211$ from the same company) was eluted with $0.35 \mathrm{~N}$ citrate $\mathrm{pH} 5.28 .2 \mathrm{ml}$ of the reaction mixture was analyzed on each column. The amount of ammonia in the reaction mixture was determined with the Nessler reagent according to standard procedure.

An aliquot of the reaction mixture was acidified with $0.1 \mathrm{~N}$ sulfuric acid followed by bubbling $\mathrm{SO}_{2}$ through the solution for $15 \mathrm{~min}$. The presence of DIHQ was determined by radiochromatography with the use of the solvent systems previously described ${ }^{2}$. The ${ }^{131} I$ containing compounds were counted in a well-scintillation counter according to standard procedure.

2. The oxidation of $D^{131} I T$ without carrier. The initial mixture for the oxidation of $\mathrm{D}^{131} \mathrm{IT}$ without carrier consisted of $0.9 \times 10^{-5} \mathrm{M} \mathrm{D}^{131} \mathrm{IT}$ and $1.4 \mu \mathrm{M} \mathrm{HRP}$ in $\mathrm{pH} 7.4,0.05 \mathrm{M}$ phosphate buffer. The oxidation was performed at $20^{\circ} \mathrm{C}$ and the volume of the buffered mixture was $3 \mathrm{ml}$. The oxidation was started by the addition of $0.03 \mathrm{ml}$ of $0.05 \mathrm{M}$ hydrogen peroxide. After $90 \mathrm{~min}$ another $0.03 \mathrm{ml}$ of hydrogen peroxide was added. After $0,3,10$, $35,90,95$, and $150 \mathrm{~min}$ aliquots of $0.2 \mathrm{ml}$ were taken and acidified with $0.05 \mathrm{ml} \mathrm{N}$ sulfuric acid in order to stop the reaction. The aliquots were analyzed by radiochromatography in the following systems:

$A$. Collidine:water $(100: 35.5 \mathrm{v} / \mathrm{v})$ in an atmosphere of ammonia ${ }^{6}$.

$B$. tert.-Amyl alcohol saturated with $2 \mathrm{~N}$ ammonia ${ }^{8}$.

$C$. Acetic acid:pyridine:water $(1: 10: 89 \mathrm{v} / \mathrm{v})^{4}$.

$D$. Two-dimensional system with

1. = system $C$.

2 . = Benzene saturated with water.

$E$. Two-dimensional system with (after $\mathrm{SO}_{2}$ bubbling of the aliquot)

1. Heptane:propanol:acetic acid: $0.001 \mathrm{M}$ sodium thiosulfate (100:50:1:100 v/v organic phase) ${ }^{2}$.

2. Benzene: $0.001 \mathrm{M}$ sodium thiosulfate (1:1 v/v organic phase) ${ }^{2}$.

Only the last aliquot was tested in system $E$. In all chromatographic systems control experiments were made with a ${ }^{131} \mathrm{I}$-solution previously incubated with HRP and hydrogen peroxide. The control experiment. was made in order to investigate the possibilities of some of the compounds being formed from oxidation products of iodide ? 


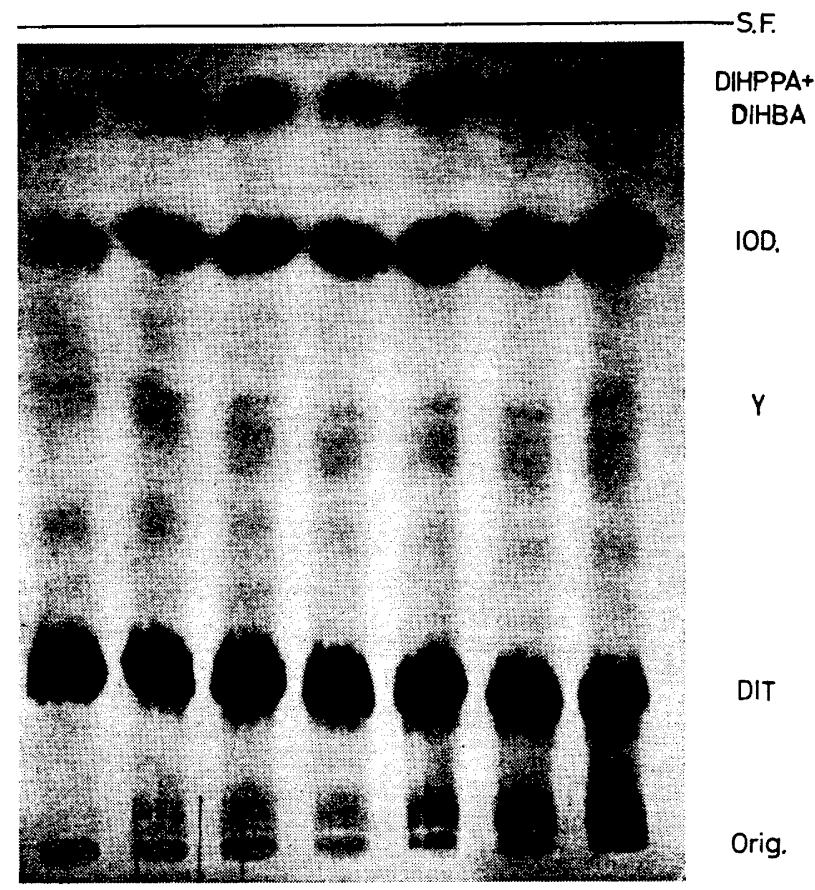

Fig. 1. Radiochromatogram showing the oxidation products of $\mathrm{D}^{131} \mathrm{IT}\left(2.5 \times 10^{-3} \mathrm{M}\right)$ at different time intervals.

3. Oxidation of alanine and serine. $3 \mu$ mole alanine and $3 \mu$ mole serine were incubated in $6 \mathrm{ml} 0.05 \mathrm{M}$ phosphate buffer ( $\mathrm{pH} 7.4$ ) with $0.8 \mu$ mole $\mathrm{HRP}$ and $0.06 \mathrm{ml} 0.05 \mathrm{M}$ hydrogen peroxide for $3 \mathrm{~h}$ at $20^{\circ} \mathrm{C}$ in order to determine if these amino acids were oxidized. $2 \mathrm{ml}$ of the reaction mixture were analyzed by column chromatography employing the long column.

4. Oxidation of DIHPPA. The initial mixture for the oxidation of DIHPPA consisted of $1 \times 10^{-4} \mathrm{M}$ DIHPPA and $0.9 \mu \mathrm{M}$ HRP in $3 \mathrm{ml} 0.05 \mathrm{M}$ phosphate buffer, $\mathrm{pH} 7.4$. The oxidation was initiated by adding $0.03 \mathrm{ml}$ of $0.05 \mathrm{M}$ hydrogen peroxide to the solution. The reaction course was followed at $345 \mathrm{~m} \mu$ in a Beckman DU spectrophotometer. At this wavelength DIHBA has an absorption maximum which distinguishes it from DIHPPA and DIBQ.

In this investigation DIBQ has been identified as DIHQ due to the difficulties in chromatographing the DIBQ compound.

\section{RESULTS}

1. The oxidation of $D^{131} I T$ with carrier. The eluate from the long column did not reveal any ninhydrin positive material. Thus alanine, serine, and tyrosine were not present. (With this determination method $1 / 16 \mu$ mole of an amino acid can be detected with certainty but amounts down to about 5/1000 $\mu$ mole can be revealed). The eluate from the short column contained $9 \mu$ mole DIT, about $0.3 \mu$ mole MIT, ammonia, and a small amount of an unidentified, 


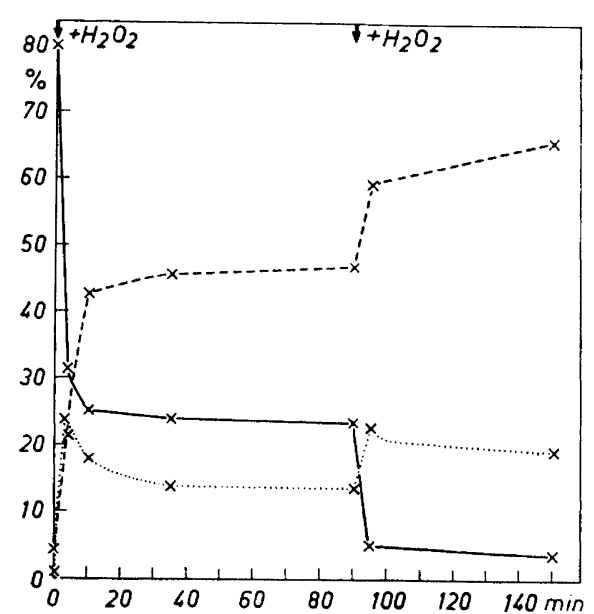

Fig. 2. Relative activity curves of the three main oxidation products of $D^{131} I T$ $\left(0.9 \times 10^{-5} \mathrm{M}\right)$ at different time intervals.

$$
\begin{array}{ll}
- & \text { D }^{131} \mathrm{IT} \\
\ldots-- & \text { Iodide } \\
\ldots \ldots & \text { DIHPPA + DIHBA }
\end{array}
$$

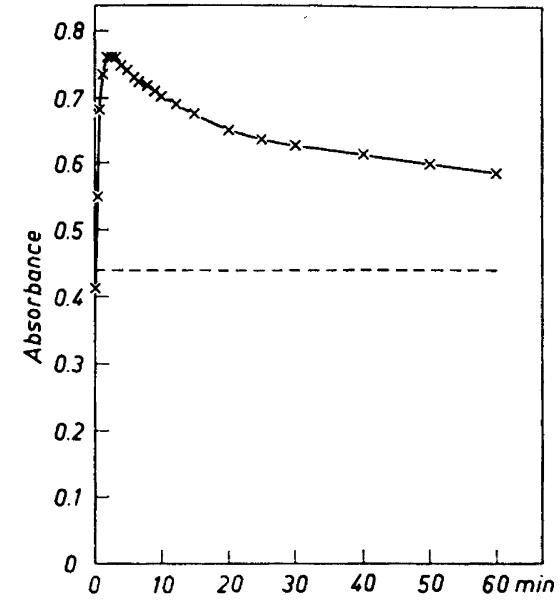

Fig. 3. Oxidation of DIHPPA followed at $345 \mathrm{~m} \mu$.

Oxidation with peroxidase and hydrogen peroxide.

- - Oxidation with hydrogen peroxide.

ninhydrin positive compound. (The values are calculated for the whole $12 \mathrm{ml}$ volume.) The unidentified compound moved faster than ammonia and DIT. The amount of ammonia in the reaction mixture, determined with the Nessler reagent, was found to be $2.9 \mu$ mole. For this determination the initial reaction mixture without hydrogen peroxide was used as blank solution.

An example of a radiochromatogram developed in the collidine: water solvent is presented in Fig. 1. The presence of DIT, iodide, a spot with the same $R_{F}$ value as DIHPPA and DIHBA, and spots at or near the origin may be observed. Compound Y (Fig. 1) was also found in the blank experiment in which ${ }^{131}$ I was oxidized with peroxidase and hydrogen peroxide. The same amount of this compound was found in the two experiments.

2. The oxidation of $D^{131} I T$ without carrier. The results from the radiochromatogram developed with the collidine system are given in Fig. 2. The percentage of the total activity which corresponded to the three main components at different time intervals may be observed. In the collidine system DIHPPA and DIHBA have the same $R_{F}$ value and were thus determined together.

The result from the radiochromatogram developed with system $E$ showed that $13.6 \%$ of the total activity was in the DIHQ fraction after $150 \mathrm{~min}$.

In the tert. amyl alcohol system a dark spot appeared which exactly corresponded to that of DIHPPA and DIHBA. The two compounds have the same $R_{F}$ value $(0.66)$ in this system. In the pyridine system DIHPPA and DIHBA could be separated $\left(R_{F}, 0.67\right.$ for the aldehyde and 0.80 for the keto acid). It was difficult to get reliable quantitative data from this system due to the interference of DIT $\left(R_{F} 0.73\right)$. DIHPPA and DIHBA were also qualita- 
tively separated by two-dimensional radiochromatography with system $D$. In the benzene system the aldehyde has $R_{F} 0.82$ and the keto acid 0.05 .

3. The oxidation of alanine and serine. Alanine and serine were not oxidized by the peroxidase-hydrogen peroxide system.

4. The oxidation of DIHPPA. The results of the spectrophotometric determination at $345 \mathrm{~m} \mu$ are give in Fig. 3. DIHPPA was first oxidized to DIHBA and then to DIBQ. DIHBA was also identified by paper chromatography in the pyridine system and DIBQ was converted to DIHQ at $\mathrm{pH} 2$ by bubbling $\mathrm{SO}_{2}$ through the solution as described above and chromatographed in system $E$.

\section{DISCUSSION}

The formation of DIHPPA from DIT by the action of $l$-amino oxidase has previously been described ${ }^{9}$ and verified ${ }^{4,6}$. However, the reservation must be made that by using alkaline solvent systems for chromatographic identification, the conversion of DIHPPA to DIHBA takes place almost instantaneously 4 . The two compounds have the same $R_{F}$ value in the systems used by these authors. The same reservation must also be made for the work by Haney and Lissitzky ${ }^{8}$ who isolated DIHPPA from the thyroid gland of rat and identified the compound by radiochromatography using tert. amyl alcohol saturated with $2 \mathrm{~N} \mathrm{NH} \mathrm{NH}_{4} \mathrm{OH}$.

The formation of DIBQ from DIHBA is in agreement with the behaviour of other substituted benzaldehydes. Thus Dakin ${ }^{10}$ observed that dichloro- and dibromobenzaldehyde gave the corresponding quinols when oxidized with hydrogen peroxide. In the presence of peroxidase and hydrogen peroxide, dimethylbenzaldehyde give good yields of dimethylbenzoquinone ${ }^{11}$. It has been verified that with only hydrogen peroxide, diiodo- and dimethylbenzoquinone are not formed.

The formation of DIHBA from DIT has previously been described by Pitt-Rivers ${ }^{12}$ who incubated DIT in the presence of a large amount of hydrogen peroxide at $100^{\circ} \mathrm{C}$ at $\mathrm{pH} 14$. Under these drastic conditions DIHPPA is not stable and it is difficult to say if this compound is formed. Oxalic acid and alanine were also identified from the reaction mixture. In the present investiga-

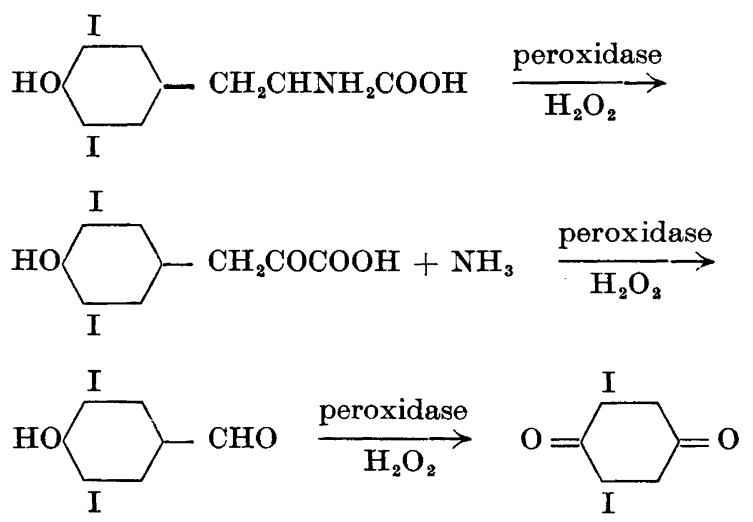

Acta Chem. Scand. 17 (1963) No. 3 
tion neither oxalic acid nor alanine were detected. The unknown ninhydrin positive compound, found by column chromatography, seems to have the same $R_{F}$ value as alanine in butanol: acetic acid: water $(4: 1: 1 \mathrm{v} / \mathrm{v})$. This may account for the finding of alanine in the earlier investigation ${ }^{1}$.

The present investigation suggests that the reaction mechanism for the formation of DIBQ from DIT is the one given above.

It is not known if the reaction occurs in vivo but both DIHPPA ${ }^{8}$ and DIBQ (as DIHQ) ${ }^{2}$ have been isolated from the thyroid gland.

The formation of thyroxine from DIT and DIHPPA in the presence of oxygen has previously been described ${ }^{4,13,14}$. In the present investigation the use of the unphysiological high concentrations of peroxidase and hydrogen peroxide rapidly converts DIHPPA to DIHBA, and thyroxine is also degraded by this oxidation system ${ }^{15}$. The presence of peroxidase in the thyroid gland seems now to have been well established ${ }^{16-18}$.

Acknowledgements. The author wishes to thank Professor Hugo Theorell for valuable help and criticism. Thanks are also due to Dr. B. Sörbo for instructive discussions and to Dr. G. Kresheck for reviewing the language. During part of the work able technical assistance has been given by Miss Anne-Marie Fridén.

This investigation has been supported by a grant from Karolinska Institutets Lärar. kollegium and is acknowledged with grateful thanks.

\section{REFERENCES}

1. Ljunggren, J. G. Acta Chem. Scand. 11 (1957) 1072.

2. Ljunggren, J. G. Acta Chem. Scand. 15 (1961) 1772.

3. Paal, C. Ber. 28 (1895) 2407.

4. Shiba, T. and Cahnmann, H. J. J. Org. Chem. 27 (1962) 1773.

5. Spackman, D. H., Stein, W. H. and Moore, S. Anal. Chem. 30 (1958) 1190.

6. Nakano, M., Danowski, T. S. and Utsunii, H. Endocrinology 65 (1959) 242.

7. De Groot, L. J. and Berger, J. E. Endocrinology 67 (1960) 657.

8. Haney, J. and Lissitzky, S. Biochim. Biophys. Acta 63 (1962) 557.

9. Tong, W., Taurog, A. and Chaikoff, I. L. J. Biol. Chem. 207 (1954) 59.

10. Dakin, H. D. Am. Chem. J. 42 (1909) 477.

11. Booth, H. and Saunders, B. C. J. Chem. Soc. 1956940.

12. Pitt-Rivers, R. Biochem. J. 43 (1948) 223.

13. Meltzer, R. I. and Stanaback, R. J. J. Org. Chem. 26 (1961) 1977.

14. Shiba, T. and Cahnmann, H. J. Biochim. Biophys. Acta 58 (1962) 609.

15. Lamberg, B. A., Gräsbeck, R., Björksten, F. and Karlsson, R. Acta Endocrinol. Suppl. 67 (1962) 160.

16. Klebanoff, S. J., Ylip, C. and Kessler, D. Biochim. Biophys. Acta 58 (1962) 563.

17. Hosoya, T. and Ui, N. Nature 192 (1961) 659.

18. Alexander, N. M. J. Biol. Chem. 234 (1959) 1530.

Received November 23, 1962. 